\title{
Splitting consciousness: Unconscious, conscious, and metaconscious processes in social cognition
}

\author{
Piotr Winkielman ${ }^{1}$ and Jonathan W. Schooler ${ }^{2}$ \\ ${ }^{1}$ University of California, San Diego, CA, USA \\ ${ }^{2}$ University of California, Santa Barbara, CA, USA
}

\begin{abstract}
This paper explores the interplay between unconscious, conscious, and metaconscious processes in social cognition. We distinguish among mental states that are (i) genuinely unaware, (ii) aware, but lack meta-awareness, and (iii) meta-aware - internally articulated as states of the perceiver. We review key studies from our own and related research programmes to highlight this theoretical framework, and to illustrate access, translational, and temporary dissociations between levels of awareness. The discussed phenomena include unconscious affect, mind-wandering, verbal overshadowing, theory-based biases in reporting of experiences, and many others. We also show how our framework can offer new perspectives on some classic social psychology findings and inspire discovery of new findings. However, we also highlight challenges inherent in establishing whether a phenomenon is genuinely unconscious or experientially conscious but lacking in meta-awareness.
\end{abstract}

In daily life, and in scientific studies, people are frequently asked questions like "'How do you feel right now?", "Do you want to smoke?", “Do you find this person attractive?", "Did you enjoy this piece of music?", "Did you notice this object?", "Do you understand this passage of text?" These standard questions require the ability of the person to access, evaluate, and express the contents of his or her own mind. Although this process is usually effortless, and thus might appear simple, it is actually tricky. After all, not all mental states are conscious, and even those that are conscious can be so in

Correspondence should be addressed to Piotr Winkielman, Department of Psychology, University of California, San Diego, 9500 Gilman Drive, Mailcode 0109, La Jolla, CA 920930109, USA. E-mail: pwinkiel@ucsd.edu

Support was provided by NSF grant to P.W. (BCS-0350687) and SHRCC grant to J.S. This paper greatly profited from discussions of these issues with Shlomi Sher. We thank Ben Baird, Robert Balas, Liam Kavanagh, and Galit Yavne for comments and corrections.

(C) 2011 European Association of Social Psychology 


\section{WINKIELMAN AND SCHOOLER}

various forms and to different degrees. To shed some light on these complexities, this chapter reviews research that has explored the interplay between unconscious, conscious, and metaconscious processes in social cognition. The theoretical perspective offered here reflects many years of discussions between the authors about the function of consciousness in a variety of social, cognitive, and affective phenomena. Each of us has an individual research programme that deals with these issues, and reviews of those separate programmes are available elsewhere (Schooler \& Schreiber, 2004; Winkielman, Berridge, \& Wilbarger, 2005a). In contrast, what we offer here is a unique review of overlapping aspects of our research from the perspective of a very basic question in psychology: How does one establish whether a person is conscious of something? For example, whether a person is conscious of an emotional state, like their anger, a motivational state, like their craving for a cigarette, or a cognitive state, like the meaning of text they just read?

In the current review we will provide some paradigmatic examples from our past empirical work to highlight a theoretical framework on consciousness that distinguishes among several levels of awareness. This view will be elaborated on shortly, but for now it is enough to say that we assume the following. Some mental states can be genuinely unaware-not accessible even to a skilled, accuracy-motivated, and attentive perceiver. Other states, however, are aware, but lack meta-awareness, by which we mean that they are not accompanied by an explicit thought of being in that state. As a result these states, and behaviour resulting from these states, are sometimes misinterpreted as reflecting unconscious processes. Finally, some mental states are meta-aware-internally articulated as states of the perceiver (Schooler, 2001).

Our perspective is informed by recent developments in social and cognitive psychology, particularly in the area of metacognition where the central effort is to uncover the relation between people's mental states and their beliefs about those mental states (Koriat, 2006). We also draw on new discoveries in neurosciences, which suggest specific neural systems involved in unconscious, conscious, and meta-conscious states. Our perspective not only allows us to capture and predict interesting theoretical findings but also offers a fresh and respectful view on consciousness, which recently has been treated in much of social psychology with a somewhat dismissive attitude (unlike in other sciences, where interest in mechanisms of consciousness is growing). We also hope to move beyond the dichotomy of unconscious vs conscious processes that is assumed in many social psychology papers.

Here is a brief outline of the paper's structure. We start by specifying our use of the term "conscious". Next we elaborate on the distinction between the levels of awareness. This allows us to then explain the possibility of dissociations between different levels of awareness. We then illustrate each 
dissociation with examples from our empirical research. We close by highlighting some areas of disagreement and point out some directions for future work.

\section{DEFINITION, LEVELS OF CONSCIOUSNESS, DISSOCIATIONS BETWEEN LEVELS}

\section{The meaning of conscious}

The adjective "conscious" has multiple meanings (Zeeman, 2002). However, in the context of this chapter it refers to the subjective status of a particular mental content (perception, thought, or feeling). Being conscious means being represented in a "subjectively privileged" way in internal experience. This first-person, privileged way is associated with several features. For one, the person directly "sees", "knows", or "feels" a particular mental content (e.g., anger) rather than having to indirectly infer it, say, from behavioural cues ("I am flailing my arms, thus I must be angry"). This idea of a subjectively special status of conscious mental content typically implies its wide and flexible availability (Baars, 1988). Thus conscious mental content is potentially available to report (verbal and nonverbal). It can be talked about, danced about, painted, expressed in music, etc. It can also be used in intentional control of behaviour. Finally, conscious mental content can be flexibly combined with other pieces of information. It is in that sense of "subjective availability" that psychologists are interested in the distinction between conscious and unconscious perceptions, memories, goals, attitudes, or emotions (Bargh, 1989; Greenwald, 1992; Winkielman \& Berridge, 2004).

\section{Levels of awareness}

As mentioned, our view goes beyond the conscious-unconscious distinction by assuming that mental content can stand in one of three relations to consciousness. This relation is illustrated in Figure 1.

First, mental content can be genuinely unconscious. One classic general psychological example comes from research on so-called "blindsight" patients with damaged primary visual cortex (area V1 of striate cortex) but intact subcortical visual pathways. These patients can discriminate simple visual information (e.g., location, or shape) and use it in their motor pointing behaviour, without being able to verbally report on that discrimination (Weiskranz, 1986). In that case, the mental representation (e.g., " $\mathrm{x}$ is a square") is genuinely unconscious - the patient truly does not know that he or she "knows" what shape was presented.

Second, mental content could be "experientially conscious", existing in ongoing experience without being reflected upon. For example, pre-verbal 


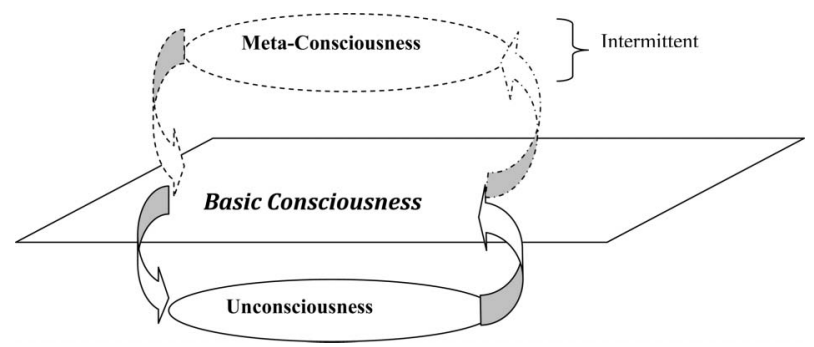

Figure 1. Relationship of different levels of awareness (after Schooler, 2002).

infants are typically assumed to have conscious experiences (e.g., feel hunger and pleasure) but limited meta-awareness. A less-speculative example comes from classic experiments on iconic memory, which showed that people are temporarily aware of a much larger amount of information presented in a visual matrix than they can spontaneously report (Sperling, 1960).

Third, mental content can be "meta-conscious" (or "meta-aware") and be explicitly represented as a content of one's own consciousness (Schooler, 2001, 2002). It is this type of consciousness that is typically assessed when an experimenter asks participants questions like, "How happy do you feel now?", "Did you notice any briefly presented words?", or "Did you pursue goal X in your behaviour?"

\section{Dissociations between levels of awareness}

The above discussion highlights that at any given moment individuals' behaviour can reflect a variety of influences. There is the unconscious information, which can be used for routine operations (Bargh, 1997). There is also information in their stream of consciousness (experiential consciousness). Periodically, however, we need to explicitly attempt to answer the question "What am I thinking or feeling?" Given that this answer represents a description of one's state, rather than the state itself, it offers individuals the opportunity to step out of the situation. This may be critical for many behaviours that require control (e.g., "I am not doing what I am supposed to be doing") but also for many innovative behaviours of which individuals are capable. However, it also raises the possibility that in the re-description process individuals might get it wrong.

More specifically, there are three kinds of dissociations between levels of mental representation. There are access dissociations in which a mental state occurs, and has an influence on behaviour, but is never directly accessed by consciousness. There are also two additional dissociations that follow from the claim that meta-consciousness involves the intermittent re-representation of the contents of consciousness (Schooler, 2002). Temporal dissociations occur 
when meta-consciousness temporarily fails to take stock of the current contents of thought (e.g., failing to notice that one is mind-wandering during reading). Translation dissociations occur if the meta-representation process misrepresents the original experience. Such dissociations are particularly likely when one verbally reflects on nonverbal experiences or attempts to take stock of ambiguous experiences. We will shortly discuss concrete empirical examples of such dissociations. Before that, let us first clarify several theoretical assumptions and make some additional distinctions.

\section{THEORETICAL CLARIFICATIONS AND DISTINCTIONS}

The distinction between unconscious, conscious, and meta-conscious mental states raises a host of interesting issues of clarification (for further discussions, see Chin \& Schooler, 2009; Schooler, 2001, 2002; Schooler, Ariely, \& Loewenstein, 2003; Schooler \& Mauss, 2010; Schooler \& Schreiber, 2004, 2005). However, the following provides an overview of several of the most central issues.

\section{Is meta-consciousness a distinct mental state?}

We are not claiming that the distinction between meta-conscious and conscious states is of the same sort as that between consciousness and unconsciousness. There is a profound qualitative difference between conscious and unconscious mental states; the former are associated with a defining aspect of our existence (namely experience), whereas the latter are lacking this fundamental quality. In contrast, the distinction between consciousness and meta-consciousness is simply one of content. Metaconsciousness can be said to correspond to conscious states in which the content of those states includes an explicit characterisation of what is currently being experienced. In other words, meta-consciousness is simply a kind, albeit a very important kind, of conscious experience in which the focus of thought is turned onto itself. Thus, while conscious and unconscious mental processes are categorically distinct, conscious and meta-conscious states only differ with respect to the type of content that they entail.

Nevertheless, as we will show shortly, this distinction has theoretical significance as it provides a conceptual pivot point for thinking about many psychological phenomena. It also has a practical significance, as it carries behavioural consequences. For example, consider an employee who fails to become meta-aware of his anger or a student who fails to become metaaware of her mind-wandering during reading. In both cases, meta-awareness 
would likely trigger beneficial attempts at self-control. On the other hand, a person who becomes meta-aware during a pleasure experience may actually enjoy it less than a person who is not explicitly monitoring his or her state (Schooler et al., 2003).

\section{Is the transition to meta-consciousness gradual or abrupt?}

Because meta-consciousness simply corresponds to a category of mental content it can be expected to enter consciousness in a manner similar to that of other mental contents. In some cases mental contents can gradually come to mind, as when we experience the dawning recognition of an inchoate idea. In other cases mental contents can spring to mind quite suddenly, as when insights pop out of the blue. Meta-conscious contents have this same range of properties. In some cases one may gradually gain meta-awareness of a particular mental state, for example as a person slowly comes to realise that she is hungry or tired. In other cases, meta-consciousness of a particular state may arise quite abruptly as when during a long drive a person suddenly realises that he mind-wandered right past the motorway exit.

\section{What triggers meta-awareness?}

Whether gradual or abrupt, the transition to meta-awareness is facilitated by several factors. One is the strength and clarity of the internal state. Fast, weak, fuzzy experiences (e.g., a flash in the visual periphery, hum of a distant plane, subtle scent of a perfume) may first be unconscious, and then remain on the "fringe of consciousness" (Mangan, 2001). Such experiences become noticed and articulated in meta-awareness only when they become stronger and clearer, either via their bottom-up strength, or via amplification by attention. These ideas are related to several notions in cognitive psychology. One is the idea of "consciousness as global ignition", according to which it takes a strong mental state to become globally available, including to the verbal and nonverbal reporting systems (Dehaene, Changeux, Naccache, Sackur, \& Sergent, 2006). Another notion is the idea that conscious representations are robust and distinct (Cleeremans, 2005). And, of course, there is the classic notion that consciousness involves transition from parallel to serial, controlled processing (Shiffrin \& Schneider, 1977). These are all important factors. However, we emphasise again that in our framework meta-awareness has less to do with sheer strength, robustness, or style of processing than with the "orientation" of the thought (onto itself). As such, our approach is more related to the idea that what makes a state meta-conscious is a particular kind of recurrent processing, where a mental state is maintained and boosted by a network of processes targeting that state (Lamme, 2004). A critical component of that 
process would be the ability to connect to the working memory contents, such as current goals (Hazy, Frank, \& O'Reilly, 2007). In fact, by the very definition, states like mind-wandering involve a failure to link ongoing experience with the current goals.

It is also worth noting here that our view does not require that metaaware states are represented in a linguistic form. Meta-awareness requires an ability to make certain conceptual distinctions (e.g., "It is my own thought", "It is my own feeling", "I lost track of what I am doing"), but these distinctions are not linguistic per se (for many examples of complex conceptual distinctions that do not depend on language, see Barner, Li, \& Snedeker, 2010). As such, we speculate that meta-awareness is principally possible even in organisms (human and non-human) without language. After all, one can reflect about the many shades of one's own current experience of pleasure, without having words that identify each shade of pleasure.

The second factor determining the transition to meta-awareness is the need for communication of the content of one's mental state (to others, or to oneself). A common source of meta-awareness are queries about one's mental states, such as "How are you feeling?" or "Were you paying attention to me?" By definition, any time a person reports on their internal feelings or thoughts they are engaging in meta-consciousness.

A third factor involved in the triggering of meta-conscious thoughts is self-awareness. For example, in one study participants were made to first think about their own self, via the self-reference task, whereas control participants completed this task for President Obama. Later, during a mindwandering task, the self-primed participants caught themselves mindwandering more often than control participants (Smallwood, Mrazek, \& Schooler, unpublished data). As will be discussed in more detail shortly, other studies have found that manipulations that reduce self-awareness (such as consuming alcohol) can minimise the likelihood of metaconsciousness (e.g., Sayette, Reichle, \& Schooler, 2009).

There are interesting links between the issue of transition from awareness to meta-awareness and classic social psychological literature. It is a tenet of social psychology that the ability to treat one's mind as an object is, at least to some extent, a "social skill" (Mead, 1934; Vygotsky, 1962). The need to take stock and articulate our own thoughts and feelings, and evaluate them from the perspective of a generalised other, is likely to be facilitated by requirements of social coordination (Baumeister \& Masicampo, 2010). Empirically, social psychologists have shown that self-awareness, whether induced by the presence of self-focusing devices (e.g., mirror) or as a dispositional quality, can improve access to some of people's own mental states (Gibbons, 1990), enhance veracity of their reports (Wicklund, 1975), or at least make their reports of internal states more aligned with their beliefs (Winkielman, 2002). 


\section{What is the relationship of the present distinction to other distinctions of consciousness?}

The distinction between unconscious, conscious, and meta-consciousness is just one of many possible ways of differentiating states of consciousness, and we do not present it to the necessary exclusion of alternative distinctions. Although it is beyond the scope of this review to consider its relationship to all other existing conscious distinctions, several remarks may help to situate this distinction in the larger context (for a more extensive consideration of this issue see Schooler, 2002).

First, we rush to note that there is nothing magical about the number 3 . The proposal to distinguish between unconscious, conscious, and metaconscious states is not exhaustive; additional distinctions are clearly possible. It is also not categorical; there are continuities between those states.

Second, the distinction between consciousness and meta-consciousness is closely allied with a variety of other terms that have been introduced over the years. For example, it corresponds to some usages of the difference between first-order and second-order consciousness. A very close approximation to the distinction between consciousness and meta-consciousness was presented by Lambie and Marcel (2002), who argued that individuals with alexithymia have a first order experience of emotions but lack a second order awareness of the fact that they are experiencing the emotion.

Others, however, have used the term second-order consciousness in a manner that does not directly map onto the notion of meta-consciousness. In philosophy Ned Block (1995) introduced a distinction between phenomenal consciousness (first order) and access consciousness (second order). The notion of phenomenal consciousness intends to capture the intuition that some basic conscious states are "pre-cognitive, pre-categorical, and pre-rational". They consist of subjective feelings-sensory experiences such as seeing, hearing, smelling, touching, tasting, and having pleasures, pains, wants, and aversions. These experiences have an analogue or fine-grained (high-bandwidth) nature, which makes them inherently ineffable. For example, even a basic feeling of pleasure of human touch has such fine-grained contents that it cannot be fully captured by even the most precise words. One can always distinguish (and poets do) many more shades of pleasure than people have concepts for. In contrast, access consciousness consists of cognitive (categorised, propositionalised, rational) information that is globally available in the cognitive system. As a result it can be used for the purposes of reasoning, speech, and high-level action control. As such, access consciousness consists of articulated thoughts, beliefs, acts of inner speech, etc. In an argument similar to what we offer here, Block (1995) has proposed that access consciousness and phenomenal consciousness 
might not always coincide. As a result one can have a very sharp phenomenal (perceptual) sense of something (e.g., an array of shapes in the sand) and, at the same time, a poor conceptual one (unable to name or remember any of the shapes). One can also always be alerted to some new shade of phenomenal experience (i.e., be made meta-aware). Although our distinction between consciousness and meta-consciousness clearly takes some inspiration from Block's ideas, it is also different as it does not ride on the "perceptual/conceptual" distinction. Thus one can be conscious but not meta-conscious of purely conceptual content.

Another popular distinction in philosophy is between first-order and second-order mental states. For example, Rosenthal (1986) suggests that in order to reach consciousness at all, all first-order mental states must be accompanied by a second-order state, although that second-order state need not itself be conscious. While there may exist some form of unconscious higher-order representation that is required to enable a first-order cognition to reach consciousness, such an idea is clearly very different from ours. The kind of second-order mental states that we are referring to are explicitly conscious states, and a central premise of our view is that first-order mental states can be conscious, even when they are not accompanied by explicit knowledge of their occurrence.

While some distinctions closely approximate the one being promoted here, others are quite different yet compatible. For example, Dehaene et al. (2006) distinguishes between subliminal and preconscious processing. In brief, subliminal processing corresponds to states that are inherently insufficient to ever reach consciousness. However, preconscious processing corresponds to mental activity that is sufficient to produce experiential states, had attention been directed towards it. This distinction of alternative states of unconscious thought is potentially consistent with the present discussion as it delineates a different aspect of consciousness. Whereas the present discussion seeks to differentiate alternative varieties of conscious states, Dehaene and colleagues distinguish alternative kinds of unconscious mental processes. Our view is entirely agnostic regarding the number and type of distinct states and/or processes that may take place at the unconscious level.

While in principle compatible with the distinction between subliminal and preconscious mental states, the present account does offer a potentially alternative way of construing at least some mental states that Dehaene et al. characterise as preconscious. Accordingly, one account of states that are in principle available to consciousness, but not reported, is to assume that they are, as Dehaene suggests, not experienced. An alternative is that such states are in fact experienced, but simply fail to be reported (i.e., they lack metaawareness). As will be further discussed later, differences between access dissociations (in which mental states are not consciously experienced) and 
dissociations of meta-awareness (in which mental states are experienced but fail to be explicitly acknowledged) can be difficult to differentiate conclusively. Nevertheless, this makes the difference between them no less conceptually important. To take just one example, it may be difficult to distinguish between an anaesthetised state in which consciousness is entirely eliminated, and one that is experienced but not reported due initially to immobilisation and subsequently to amnesia. Nevertheless, the distinction remains a profound one for the individual who temporarily experiences the surgeon's knife!

In the reminder of the chapter we use the above conceptual framework to review our and related work. We will show how social cognitive phenomena illustrate the different dissociations (access, temporal, translation) between levels of consciousness in the domain of emotion, motivation, memory, autobiographical reports, comprehension, and reasoning. We will also highlight several implications of this work to other areas of social psychology, including self-awareness, well-being appraisals, attitudes, stereotyping, prejudice, and thought control.

\section{ACCESS DISSOCIATIONS}

As discussed, an "access dissociation" occurs when a mental state has a demonstrable influence on behaviour, but cannot be directly accessed by consciousness. It is now almost universally accepted that many perceptual and cognitive operations can occur without individuals being conscious (Kihlstrom, 2007). Earlier in this chapter we mentioned the example of "blindsight" (Weiskranz, 1986). Another classic example is patients with visual agnosia who cannot consciously recognise objects, but have largely intact sensorimotor abilities and can pursue actions in response to these "unconscious" objects (Milner \& Goodale, 1995).

But what about affect? There is certainly research suggesting that briefly presented affective stimuli can work as unconscious triggers of conscious affective states (Kihlstrom, 2007; Öhman, Flykt, \& Lundqvist, 2000; Zajonc, 1994). But can affect itself be consciously inaccessible? In recent years one strand of our work focused on exploring a dissociation that occurs when a person is in a demonstrable affective state (as evidenced by its impact on behaviour, physiology, and cognition) without having conscious access to that state (for a comprehensive discussion see Winkielman et al., 2005a). The idea of "unconscious affect" may initially seem strange - after all, how can there be feelings that are not felt? Note, though, that evolutionarily speaking, conscious representations of affect in the form of a "feeling" is a late achievement compared with the ability to respond affectively to relevant stimuli, which is presented in animals as simple as fish and reptiles. Accordingly, the basic affective neurocircuitry is contained in the subcortical 
brain, and can operate even in the absence of cortex (Berridge, 2003). A reader interested in a recent review of neuroscientific evidence for "unconscious emotion" may wish to consult Winkielman, Berridge, and Sher (2011).

However, evolutionary and neuroscientific considerations can only be suggestive of unconscious affect in typical humans. So we embarked on a programme of psychological research to test this possibility using standard experimental paradigms with normal college participants.

\section{Impact of subliminal affective stimuli on behaviour, but not on subjective experience}

One way of testing an "access dissociation" involves separating the impact of simple affective stimuli on behaviour from their impact on conscious feelings. This was done in a series of studies by Winkielman, Berridge, and Wilbarger (2005b). The procedure of Study 1 in that paper is shown in Figure 2. As one can see, participants were presented with a series of eight happy, neutral, and angry emotional facial expressions shown at subliminal durations (16 ms). These priming faces were masked with neutral faces shown for 400 milliseconds, long enough to be seen consciously. Participants were told that their task was to guess the gender of the neutral face. That gave them something to concentrate on and provided a plausible cover story. This procedure succeeded in keeping emotional presentations subliminal. When questioned later, participants denied ever having seen the emotional expressions. More important, participants performed at chance in a forced-choice task of face recognition, which tested their ability to guess the identity of the presented faces.

Immediately after the subliminal affect induction participants were presented with two counterbalanced tasks. One task required participants to report conscious feelings - a measure of introspective access to the current affective state. Specifically, participants were asked to evaluate their current state on an 11 -point scale $(-5=$ unpleasant, $5=$ pleasant $)$. They also rated their current arousal on a similar scale $(-5=$ low, $5=$ high $)$. The other task was designed to provide a measure of behavioural impact of the current affective state. Specifically, participants were presented with a pitcher of fruit-flavoured drink (actually lemon-lime KoolAid), and asked to pour themselves as much as they wanted and to drink as much as they wanted.

The results of the study, displayed in Figure 3, illustrate that subliminal emotional expressions can influence people's pouring and drinking behaviour. Interestingly, the impact of primes on consumption behaviour increased with participants' thirst - consistent with other research suggesting that motivation amplifies the potency of affective cues. At the high level of thirst (1 SD above the mean), subliminal happy facial expressions caused 
thirsty participants to pour roughly double amount of the fruit-flavoured drink into their own cup than did angry facial expressions. After being exposed to subliminal happy expressions, thirsty participants also drank about double the amount they did when exposed to angry expressions. Importantly, participants reported no conscious awareness of any intervening change in their subjective state, as measured by their reports of valence

\section{Study Procedure}

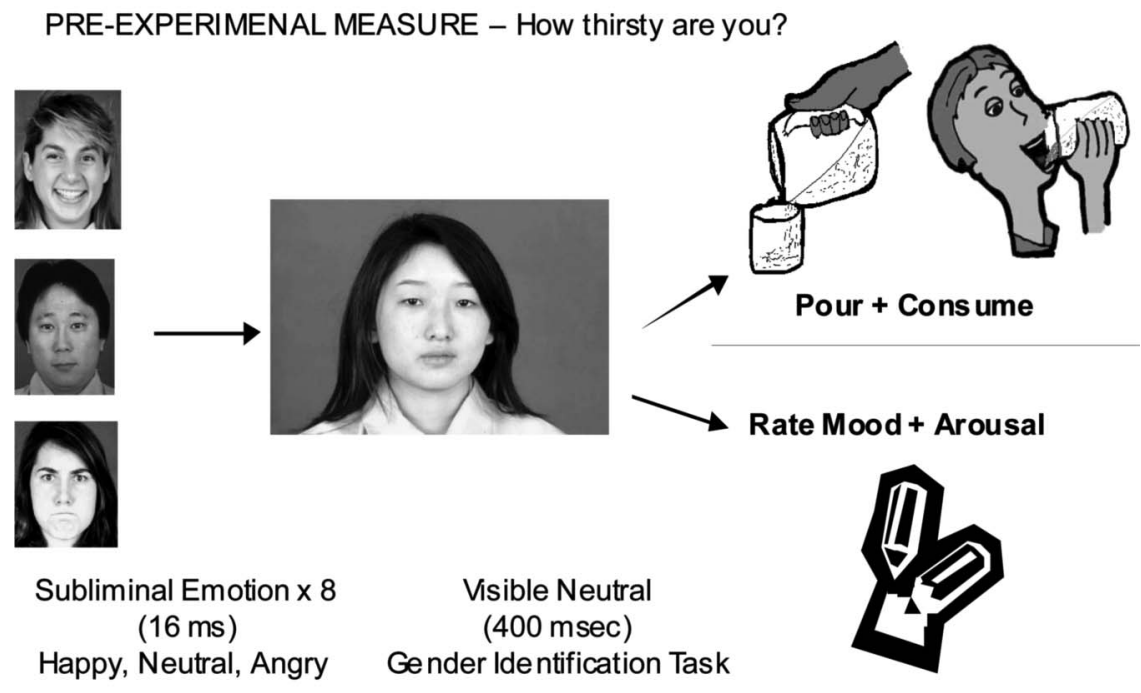

Figure 2. Procedure of studies exploring the relation between unconscious affect and behaviour (after Winkielman et al., 2005b).
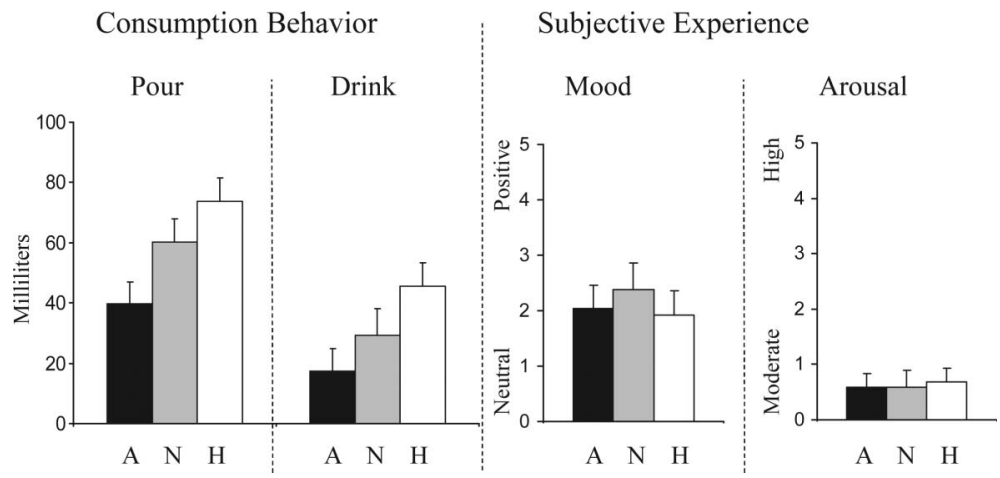

Figure 3. The impact of affective primes on consumption behaviour and conscious experience (after Winkielman et al., 2005b, Study 1). 
and arousal. That is, they did not report feeling more pleasant (or aroused) after happy facial expressions than angry expressions.

\section{Impact of subliminal stimuli on evaluation of the target stimulus, without changes in subjective experience}

The study just described suggests that consciously inaccessible affective states can drive behaviour. However, how exactly can unconscious affect do it? After all, the behaviour itself (pouring, drinking) is consciously mediated, in the sense that it requires the ability to understand verbal instructions, form an intention, execute a complex movement, etc. To understand this processes we tested the idea that unconscious affect directly modifies the subjective value of presented options, without changing conscious feelings. In Study 2 we presented people with the same series of subliminal happy or angry faces embedded in the gender identification task. After the primes some participants first reported their subjective experience on an expanded 20question PANAS (positive and negative affect) rating scale (Watson, Clark, $\&$ Tellegen, 1988). Other participants, however, were first given just a single sip of the fruit beverage, and asked to rate immediately how much they liked it, how much they wanted to consume, and how much they would be willing to pay for a hypothetical can of the beverage (again the order of drink presentation and mood ratings were counterbalanced). The results, presented in Figure 4, showed that the subliminal expressions influenced the ratings of the drink, with the effects again strongest for thirsty participants. For example, in answer to the question "How much would you pay for a can of this drink?", thirsty participants were willing to pay more in the happy than angry expressions condition (about 40 US cents versus 10 cents per can). Thirsty participants also gave higher ratings to the question "How much of this drink do you want to drink right now?" after the happy expression (about half a cup) versus angry subliminal stimulus (about one or two sips). Again, no changes in subjective emotion were produced in these thirsty participants, even when assessed by the sensitive 20 -item PANAS questionnaire. In sum, this study supported the idea that unconscious affect works via change in the perception of desirability and value of presented options, without manifesting itself as a change in subjective experience. These ideas are consistent with other work from social psychology suggesting that unconscious cues can interact with affective and motivational states in determining goal-oriented behaviour (Custers \& Aarts, 2010; Ferguson, 2007).

\section{True dissociation or lack of meta-awareness?}

However, one can ask whether participants in the above studies had no fundamental access to their affective reaction (true access dissociation) or 


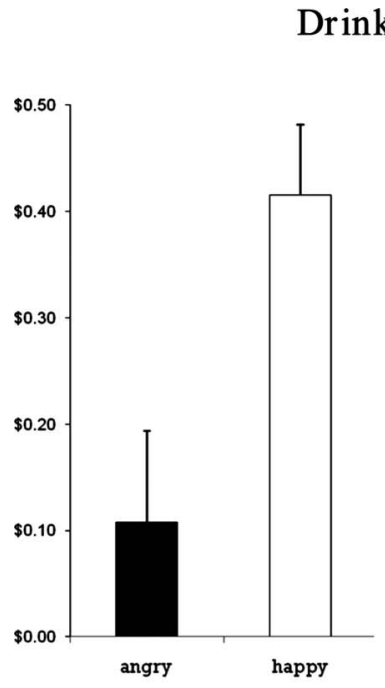

Willingness to Pay

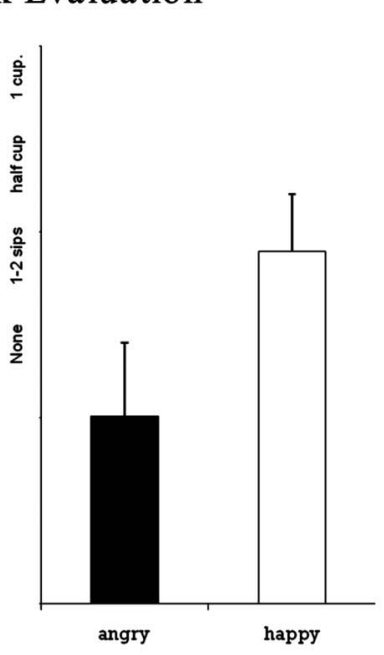

Wanting for more drink

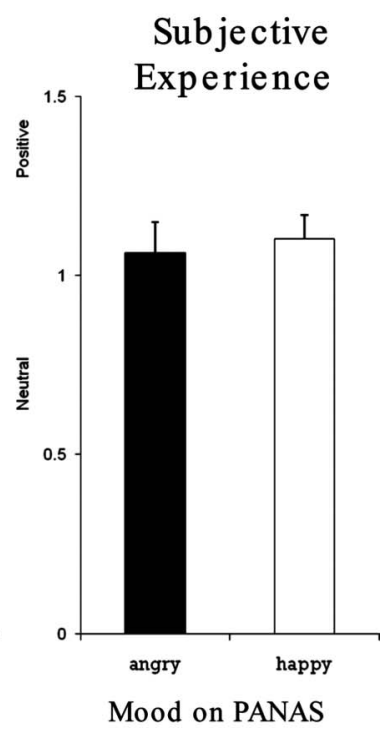

Figure 4. The impact of affective primes on drink evaluation and conscious experience (after Winkielman et al., 2005b, Study 2).

whether they simply lacked meta-awareness. After all, it is possible that participants were not attending on-line to their feelings, or did not consider their feelings as a potential impairment to their judgements and thus ignored them. Fortunately, other studies from our lab bear on this possibility (Winkielman, Zajonc, \& Schwarz, 1997). Those studies used the paradigm from Murphy and Zajonc (1993) where participants are subliminally presented with facial expressions of happiness and anger. These faces precede Chinese ideographs, which participants evaluated on a scale from 1 to 6 (like a lot). In addition our studies employed an attributional manipulation taken from social psychology (Schwarz, 1990). Participants were informed in advance about the possibility of change in their affective experience, and were given a possible cause of such change. If participants have access to their feelings, they should report them in later interviews. More important, if their feelings are consciously accessible and form the basis of their judgements, attributional manipulations should trigger corrective processes, such as discounting and augmenting. Indeed, there is evidence that participants behave in such way, as described by studies about the feeling-as-information theory (Schwarz \& Clore, 1983). However, note that the supportive studies all involve cases of strong affective manipulations (weather, recall of important autobiographical memories, powerful movies or music etc.). As a result, in those studies participants are experiencing 
conscious feelings and can not only report on them but also reason about them, as required by attributional manipulations.

In the studies of Winkielman et al. (1997) we drew participants' explicit attention to the possibility that unconscious stimuli can change their feelings and that those unconsciously elicited feelings could bias their judgement. Specifically, in Study 1 we explicitly told participants that briefly flashed subliminal stimuli could transiently change how they feel about the target ideographs. Some participants were told that the change would be positive, some that it would be negative, some that they would experience both effects, some that they would experience "something", and some participants were told nothing at all. For example, in the "positive feeling condition" participants were informed that subliminal smiling faces would briefly appear before some ideographs and may bring on "some pleasant feelings" and cause some "positive gut reactions". For this condition the attributional account predicts that participants should discount their conscious positive reactions to the ideographs preceded by positive primes, whereas their judgements of ideographs preceded by negative primes should continue to be influenced. In fact the judgements of ideographs preceded by negative primes should be especially unfavourable because, by the logic of the augmenting effect, participants should treat their negative reactions as especially diagnostic of their true liking response to the target ideographs.

The results of this study were very revealing. For one, in the postexperimental interviews participants denied experiencing changes in their affective state. That is, no participant reported experiencing any feelings as a result of the priming. Second, the pattern of judgements shows no evidence of any discounting or augmenting effects, as predicted by the attributional account. As illustrated by Figure 5, the participants responded to the expectation (attributional) instructions but did it non-specifically, by globally adjusting their judgements up or down, depending on the condition. In short, in these studies the feelings were not only absent from the selfreports of experience, but also did not enter into attributional processes, consistent with the idea that participants' affect was unconscious. For additional evidence that brief facial expressions do not produce conscious affective responses that can be used in judgments, see Bornemann, Winkielman, \& Van der Meer (in press).

\section{Physiological consequences}

One issue often raised about these findings is the nature of the unconscious emotional state. Are the unconscious states elicited by subtle and brief stimuli (like faces) simply "evaluative", in the sense of changes in activation of evaluative concepts? Or are they genuinely "emotional", in the sense of a 


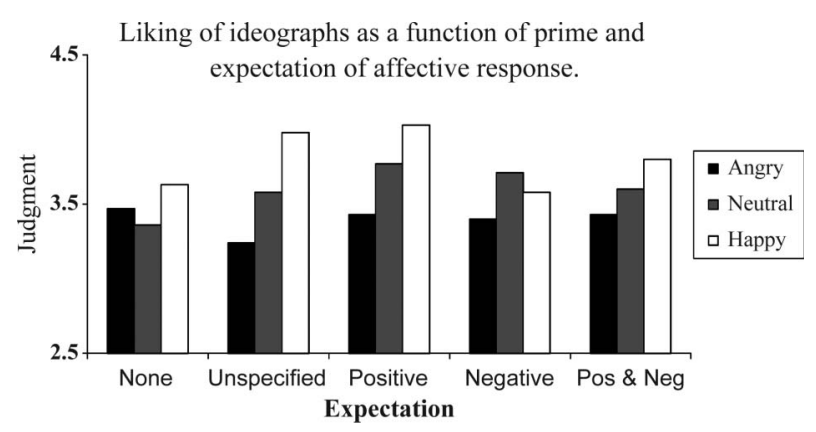

Figure 5. The impact of affective primes on target evaluation as a function of expectations about conscious experience (after Winkielman et al., 1997, Study 1, Block 1).

state that is represented across multiple physiological and psychological systems that prepare the organism for proper action? This is a difficult question, especially since almost by definition the unconscious emotional states are going to be weaker and less differentiated (Clore, 1994). Still, some recent evidence from our lab suggests that unconscious emotional states are accompanied by distinct physiological changes, and are distinguishable from pure evaluative states. Specifically, in one study we assessed the reactions to unconsciously presented facial pictures using physiological measures, such as EMG and post-auricular startle reflex - an index of activation of lowlevel positive affective system (Starr, Lin, \& Winkielman, 2007). Participants showed more smiling, and more post-auricular startle reflex, to unconscious happy rather than angry faces, suggesting genuine, albeit weak, activation of low-level affect system. Recently we followed up on this finding and presented participants with affective pictures (faces or pictures) aimed to induce an affective state, and evaluative words (adjectives and nouns) aimed to activate relevant semantic dimensions. As expected, the changes in behaviour were driven more strongly by pictures and faces, consistent with the notion that the behavioural changes reflect genuine "hot" affect, rather than cold evaluation (Starr, Winkielman, \& Gogolushko, 2008).

In sum, all these findings from behavioural and physiological experiments suggest that one can obtain genuine "access dissociation" between an underlying affective process and its conscious, experiential awareness. As such they give credence to the notion of "unconscious affect". Importantly, though, the idea of "unconscious emotion" does not imply that conscious feelings are an unnecessary "icing on the emotional cake" (LeDoux, 1996). Conscious happiness, anxiety, anger, guilt and sadness are critical in people's lives. They might well be what makes the life worth living: and we would not pay much for a substance that makes us "unconsciously happy". Conscious emotions are also useful in judgements and decisions, giving the 
decision maker valuable feedback that she might, but is not forced to, consider in her choices (Winkielman, Knutson, Paulus, \& Trujillo, 2007).

There are also several interesting implications of these ideas for the "feeling-as-information" model (Schwarz, 1990). One is that the model is obviously limited to the type of affect that is conscious. Second, some processes postulated by the model might be limited to situation where affect is not only conscious, but meta-conscious - internally articulated and categorically represented in experience. That is, whereas "by default" judgements could be based on affect that is simply experienced, the model requires that, in order to engage in corrective inferences, the current affect must be able to be understood by the perceiver as his own, potentially biasing state. Future studies might test these conjectures.

\section{TEMPORAL DISSOCIATIONS}

Sometimes mental content is consciously experienced without being explicitly appraised in meta-consciousness. Temporal dissociations are illustrated by cases in which the induction of meta-consciousness causes one to assess aspects of experience that had previously eluded explicit appraisal. Several phenomena explored in our research represent such dissociations.

\section{Mind-wandering}

We hope that readers have managed to keep their minds on our paper as they have been reading it. Yet we suspect that all readers have had the experience of suddenly realising that, despite their best intentions and the fact that their eyes have continued to move across the page, they have no idea what they have been reading. Mind-wandering suggests that the tacit monitoring systems failed to catch the mind's drifting, and instead require a higher-level explicit monitoring process to take stock of the specific contents of thought and alert one to the fact that they have wandered off-task. Over the last several years Schooler and colleagues have used the mind-wandering phenomenon to examine the function of meta-awareness in a domain where mind-wandering is antithetical to success (see Smallwood \& Schooler, 2006, for a review). Specifically, Schooler, Reichle, and Halpern (2005) developed a paradigm to identify temporal lapses of meta-awareness during the attentionally demanding task of reading. In this research participants read passages of text and indicated every time they caught their minds zoning out. They were then asked whether they had been aware that they had been zoning out prior to reporting it. In a second condition participants were additionally probed intermittently and asked to indicate whether they had been zoning out at that moment. As shown in Table 1, the results revealed 
that participants (1) frequently caught themselves zoning out during reading, (2) were still often caught zoning out by the probes, and (3) frequently reported that they had been unaware that they had been zoning out, particularly when they were caught by the probes. These findings demonstrate that individuals frequently lack meta-awareness of drifting offtask, even when they are in a study where they are specifically instructed to be vigilant for such lapses.

Additional studies have helped to further illustrate the distinct processes associated with the occurrence of mind-wandering (as revealed by probecaught episodes) and meta-awareness of mind-wandering (as revealed by self-caught episodes). The studies also examined the potential role that selfawareness plays in transition from consciousness to meta-consciousness. For example, Sayette et al. (2009) examined the impact of alcohol on participants' self-caught and probe-caught mind-wandering during reading. Alcohol was an excellent candidate as a variable likely to impact on metaawareness, given its well-established capacity to reduce people's more general self-awareness (e.g., Hull, 1981). In this study half of the participants received a beverage that included $0.82 \mathrm{~g} / \mathrm{kg}$ dose of alcohol. The other half of participants received an alcohol placebo beverage that they believed contained alcohol. Following consumption all participants were told that their blood alcohol level (BAC) was $0.045 \%$ to $0.047 \%$ (randomly assigned), which is approximately the highest credible reading for deceived participants. In fact the placebo group had a $0 \mathrm{BAC}$, whereas the participants receiving alcohol had a mean BAC of $0.067 \%$. Participants then engaged in the mind-wandering reading task in which they read War and Peace while intermittently being probed (approximately every 2-4 minutes) regarding whether they were mind-wandering. In addition participants were asked to indicate whenever they noticed that their minds were wandering. As can be seen in Table 2, alcohol had a very different effect on self-caught vs probecaught mind-wandering. Despite mind-wandering more than twice as often as participants in the placebo group (as revealed by the probe measure), participants in the alcohol group were no more likely (and indeed were slightly less likely) to catch themselves in the act. In other words, participants in the alcohol group should have had many more opportunities

TABLE 1

Frequency of self-caught and probe caught mind wandering episodes (from Schooler et al., 2004)

\begin{tabular}{lccc}
\hline & Self-caught & Probe-caught & Probe catch ratio \\
\hline Frequency & 5.35 & 1.6 & .132 \\
Maximum & 20 & 10 & .67 \\
\hline
\end{tabular}


TABLE 2

Frequency of mind-wandering of self- and probe-caught mind-wandering episodes as a function of alcohol intoxication (from Sayette et al., 2009)

\begin{tabular}{lcc}
\hline & Self-caught & Probe-caught \\
\hline Sober & 1.48 & 0.76 \\
Intoxicated & 1.24 & 1.52 \\
\hline
\end{tabular}

to catch themselves, but they did not catch themselves more often than the sober participants. Apparently they were impaired in their ability to notice mind-wandering episodes, whereas sober participants were more capable of detecting mind-wandering when it occurred. These finding illustrate the value of assessing self-caught and probe-caught mind-wandering in order to discern how various factors can impact individuals' meta-awareness of their mental states.

A related study by Sayette, Schooler, and Reichle (2010) further illustrates the value of the self-caught/probe-caught methodology for assessing the conditions that impact on meta-awareness. In addition this study explored the role of motivation in meta-awareness. Specifically, this study focused on the impact of cigarette craving on people's mindwandering and the meta-awareness thereof. Like alcohol consumption, craving is a factor that might reasonably be expected to impact on metaawareness. Nearly a dozen brain-imaging studies have reported that craving leads to activation in the anterior cingulate cortex (ACC), which has been implicated in conflict monitoring (see Wilson, Sayette, \& Fiez, 2004). Accordingly, when the ACC is focused on the conflicts inherent in the experience of craving, this may hamper recognition that one's mind has wandered (an experience that also conflicts with the stated task). More generally, craving may engage working memory and self-regulation resources that otherwise might be directed towards noticing that one has become distracted, thereby simultaneously increasing the occurrence of one's mind-wandering and decreasing the probability of catching it. To explore this issue Sayette et al. replicated the "mind-wandering while reading" task described above, but in this case half of the participants were induced into a craving state. All participants were smokers who had been asked to refrain from smoking for at least 6 hours prior to the experiment. Participants in the craving condition were not allowed to smoke prior to the experiment, whereas no-craving participants were given the opportunity to smoke. All participants were then given the reading task with both self-caught and probe-caught assessment of mind-wandering. As can be seen in Table 3, the results revealed that craving significantly impacted on participants' meta-awareness of their mind-wandering. Despite 
mind-wandering more than three times as often as participants in the nocraving condition, participants in the craving condition were not more likely to catch their mind- wandering.

These findings suggest that craving, like alcohol, disrupts individuals' meta-awareness of the current contents of thought. In so doing they also highlight possible reasons why it is so difficult to self-regulate during craving states. While conventional wisdom holds that individuals are fully aware of their cravings, some suggest that cravings can occur unconsciously (Robinson \& Berridge, 1993). This debate assumes that cravings must be either conscious or unconscious. The alternative framework suggested here - in which consciousness is divided into experiential consciousness (contents of experience) and meta-consciousness (explicit awareness of the contents of consciousness) - suggests that one can be conscious of craving but lack meta-consciousness of the fact that one is craving. Such a mental state might in turn contribute to relapses. Considerable research suggests that relapse behaviours may occur absentmindedly, with individuals failing to explicitly notice that they are relapsing (Tiffany, 1990). Traditionally, the occurrence of absentminded relapses suggested that cravings need not trigger relapse. However, the view suggested by the present perspective is that absentminded relapses may be associated with craving states in which one lacks meta-consciousness of the cravings (see Cheyene, Carriere, \& Smilek, 2006). By simultaneously promoting absentmindedness and decreasing meta-awareness, the unnoticed craving state may induce a unique condition in which individuals are maximally likely to engage in a relapse behaviour and minimally likely to notice themselves doing so.

Another approach for investigating the role of meta-awareness in mindwandering is simply to ask participants after probe-caught mind-wandering episodes whether or not they had been previously aware that their minds had drifted. Although it is not self-evident that participants would necessarily be able to accurately reflect on the prior meta-awareness of their mental states, a variety of studies suggest that they can accurately discern whether or not they were meta-aware of their mind-wandering, as evidenced by the consistent differences between mind-wandering episodes characterised as occurring with vs without meta-awareness. For example, in

TABLE 3

Frequency of mind-wandering of self- and probe-caught mind-wandering episodes as a function of cigarette craving (from Sayette et al., 2010)

\begin{tabular}{lcc}
\hline & Self-caught & Probe-caught \\
\hline Not craving & 1.18 & 0.47 \\
Craving & 1.52 & 1.48 \\
\hline
\end{tabular}


one study (Schooler, McSpadden, Reichle, \& Smallwood, 2010) participants read text one word at a time and were warned that it would periodically become gibberish (i.e., it would stop making sense). We found that although participants typically noticed the occurrence of gibberish as soon as it began, if they failed to notice it right away they often continued for several sentences before they did. Moreover, if participants were probed following extended durations of having missed gibberish, they were markedly more likely to report mind-wandering without meta-awareness than if they were probed at random intervals. Similarly, Smallwood, McSpadden, \& Schooler (2008) found that if individuals reported mind-wandering without metaawareness prior to encountering clues in a Sherlock Holmes story, they were markedly less likely to solve the mystery. Mind-wandering with metaawareness proved far less disruptive to the construction of a mental model.

When mind-wandering episodes are characterised as having proceeded without meta-awareness, they are not only more disruptive to task performance, but also more neurocognitively distinct from on-task performance. In a recent study (Christoff, Gordon, Smallwood, Smith, \& Schooler, 2009), we scanned participants while they engaged in a nondemanding vigilance task, in which they had to respond to every digit that appeared on the screen with the exception of a specific rarely presented target item for which they had to withhold a response. Because the targets are relatively rare, it is common to mind-wander during this task and then accidentally respond when a target is presented. In this study participants were periodically probed and asked whether they had been mind-wandering. In addition, if they reported mind-wandering they were further asked whether or not they had been aware of that fact. Two sets of regions were found to be more active prior to periods in which individuals reported having been mind-wandering relative to having been on-task. One was the default network - including the medial prefrontal cortex (PFC), posterior cingulate cortex/precuneus region, and the temporoparietal junction-which is known to become increasingly recruited with decreasing external task demands. This is interesting, as this network is often implicated in stimulusindependent thought (Mitchell, Mason, Macrae, \& Banaji, 2006). The second set of regions was the executive network-including the dorsal anterior cingulate cortex (ACC) and the dorsolateral PFC (DLPFC) - which becomes activated when individuals engage in demanding mental activity. Of particular interest to the present discussion were the relative differences between the activation of these areas when individuals reported being aware versus unaware of the fact that they had been mind-wandering. As can be seen in Figure 6, the discrepancy between areas of neural activity associated with on- vs off-task thought was markedly more pronounced when individuals lacked meta-awareness of the fact that they were mindwandering relative to when they knew that they were mind-wandering. 


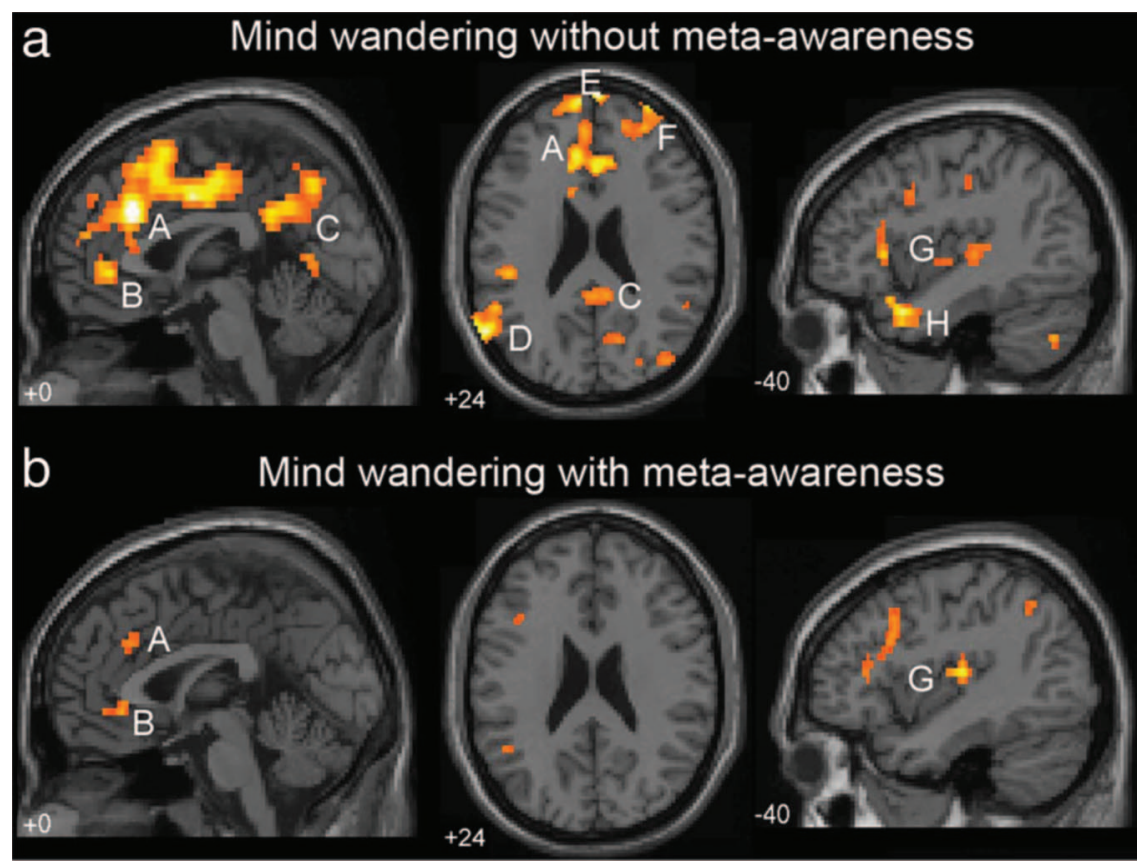

Figure 6. Mind wandering in the absence (a) and presence (b) of meta-awareness (after Christoff et al., 2009). (a) Regions of activation associated with mind-wandering in the absence of awareness (intervals prior to off-task unaware vs on-task probes) included: (A) Dorsal ACC (BA 32), (B) Ventral ACC (BA 32), (C) Precuneus (BA 7), (D) Temporoparietal Junction (BA 39), (E) Dorsal Rostromedial PFC (BA 10), (F) Right Rostrolateral PFC (BA 10), (G) Posterior and Anterior Insula, and (H) Bilateral Temporopolar Cortex. (b) Similar regions were activated during mind-wandering with awareness (intervals prior to off-task aware vs on-task probes), but to a lesser degree, including: (A) Dorsal ACC (BA 32), (B) Ventral ACC (BA 24/32), and (G) Posterior and Anterior insula. Height threshold $p<.005$, extent threshold $\mathrm{k}>5$ voxels. To view this figure in colour, please visit the online version of this article.

The fact that participants' awareness of their mind-wandering profoundly impacted on the magnitude of discrepancy between on-task versus off-task thinking offers several important implications for conceptualising metaconsciousness. First, it reveals the robustness of the distinction between those mental states that are accompanied by meta-awareness and those that are not. One might easily have conjectured that participants would have a hard time reliably characterising their mind-wandering as having been associated with meta-awareness. However, these findings suggest that this distinction was easy for participants to make. After all, mind-wandering episodes accompanied by meta-awareness (vs no meta-awareness) were associated with markedly different patterns of brain activation. Second, one might have thought that when participants were mind-wandering without 
realising it, their brains would show relatively little activity compared to being on task. On the contrary, it was during periods of mind-wandering without meta-awareness that individuals showed the maximum distinctive regions of brain activation. Apparently, while mind-wandering without meta-awareness may be especially counterproductive to ongoing task performance, the mind is far from being empty. Rather, mind-wandering without meta-awareness appears to involve a state of particularly vigorous brain activity.

\section{Well-being appraisals}

We often fail to explicitly notice our own emotional states (e.g., sullenness, cheerfulness) until someone points them out to us. If we commonly lack meta-consciousness of affective states, then it follows that inducing continuous meta-consciousness of affect may alter that experience. Schooler et al. (2003) explored this issue by asking participants to report on-line happiness while listening to hedonically ambiguous music (Stravinsky). The results showed that continuous hedonic monitoring reduced individuals' post-music ratings of happiness, relative to a condition in which participants listened to music without monitoring. The fact that hedonic monitoring altered participants' experience suggests that by default individuals are, at most, only intermittently meta-conscious of their affective state. This finding also has intriguing implications for research on well-being that involves frequent querying individuals about their current state (e.g., Kahneman, Krueger, Schkade, Schwartz, \& Stone, 2004).

\section{Unwanted thoughts}

Wegner (1994) suggested that individuals possess an implicit monitoring system that tracks unwanted thoughts (e.g., of a white bear) in order to veer away from them. But what exactly is this system monitoring? Wegner suggests that it is monitoring the contents of preconsciousness (i.e., thoughts that are near, but below, the threshold of consciousness). In a further elaboration of this view Wegner and Smart (1997) distinguished three different levels of consciousness that are related to, but distinct from, the view being presented here. From their perspective, mental states can be either present or absent in consciousness (the standard conscious/ unconscious distinction), and also associated with deep vs surface activation (i.e., the thought either does or does not have an impact on other mental states.) According to Wegner and Smart, when one tries not to think about a concept it gets relegated to a state of unconscious yet deep activation, such that the thought is not experienced but is nevertheless impactful. While such a view is certainly plausible, from the present perspective there is another 
status that unwanted thoughts might take, namely experienced but lacking in meta-awareness. That is, perhaps individuals can consciously think about a white bear, without explicitly realising that they are doing so. Such a view would then differ from Wegner and Smart's proposal in that the unwanted thought would be, in at least some cases, actually experienced but simply not acknowledged as such. Some evidence for this account comes from a study in which participants were asked to try not to think about a previous romantic relationship while reading or while simply sitting quietly (Fishman, Smallwood, \& Schooler, 2006). As in standard unwanted thought paradigms, participants were asked to self-report every time they noticed an unwanted thought coming to mind. In addition, however, they were periodically randomly asked whether at that particular moment they were having the unwanted thought. The results revealed that participants frequently experienced "unnoticed unwanted thoughts" about their previous relationship, which they experienced but failed to notice until they were probed. Further, these unnoticed unwanted thoughts were detrimental to participants' performance on a test of the reading material, suggesting again that they were conscious. Intriguingly, participants for whom the unwanted thoughts carried emotional weight (i.e., they still wished they were in the relationship) were less likely than participants who no longer wanted to be in the relationship to notice the thoughts themselves, and more likely to be caught having the thought. This suggests that cognitive defences do not banish disturbing thoughts to the unconscious, but rather prevent us from reflecting on them (Schooler, 2001).

\section{TRANSLATION DISSOCIATIONS}

The idea that meta-consciousness requires re-representing the contents of consciousness suggests that some information may become lost or distorted in the translation, as with any recoding process. The likelihood of noise entering the translation process may be particularly great when individuals (1) verbally reflect on inherently nonverbal experiences, (2) are motivated to misrepresent their experience, or (3) possess a lay theory that is inconsistent with their actual experience.

\section{Verbal reflection}

Some experiences are inherently difficult to put into words: the structure of a face, the taste of a wine, the complex tonalities of Stravinsky, and the intuitions leading to insights. If individuals attempt to verbalise these inherently nonverbal and holistic experiences, the resulting re-representations may fail to do justice to the original experience. Schooler and Engstler-Schooler (1990) examined the effects of describing faces, which, 
because of their holistic nature, are notoriously difficult to commit to words. Participants viewed a face and subsequently either described it in detail or engaged in an unrelated verbal activity. When given a recognition test that included a different photograph of the target face, along with similar distractors, verbalisation participants performed substantially worse than controls. This effect of verbalisation, termed "verbal overshadowing", has been found in variety of other domains of visual memory (Schooler, Fiore, \& Brandimonte, 1997), including colours (Schooler \& EngstlerSchooler, 1990), shapes (Brandimonte, Schooler, \& Gabbino, 1997), as well as other modalities such as audition (Schooler et al., 1997) and taste (Melcher \& Schooler, 1996). Similar disruptions resulting from verbal reflection have also been observed in various other domains hypothesised to rely on nonverbal cognition. Thinking aloud during problem solving can disrupt the intuitive processes associated with insight problem solving, while having no effect on the logical processes associated with analytical problem solving (Schooler, Ohlsson, \& Brooks, 1993). Verbally reflecting on the basis of affective judgements can interfere with quality of affective decision making, as assessed both by the opinions of experts (Wilson \& Schooler, 1991) and by post-choice satisfaction (Wilson et al., 1993). Verbally articulating the basis of the match between analogical stories can reduce people's sensitivity to meaningful deep-structure relationships, while increasing their emphasis on superficial surface-structure relationships (Sieck, Quinn, \& Schooler, 1999). Of course, in many cases verbal analysis can be helpful. This occurs when experiences are readily translated into words, due either to the nature of the task (e.g., logical problem solving; Schooler et al., 1993) or individuals' unique verbal expertise (e.g., wine experts; Melcher \& Schooler, 1996). However, our point here is that sometimes the very process of articulating experiences can result in translation dissociations, where meta-awareness misrepresents conscious content.

\section{Motivation}

In some situations individuals may want to misrepresent their experiences to themselves. For example, homophobic individuals may not want to recognise when they are aroused by depictions of homosexual acts (Adams, Wright, \& Lohr, 1996). That is, individuals may consciously experience the arousal but, because of their motivation, fail to become meta-aware of it (see also Lambie \& Marcel, 2002). Our perspective also suggests a different view of repression. Freud argued that repression prevented unwanted feelings from coming to consciousness, but we would say that it primarily prevents such feelings from reaching meta-awareness (Schooler, 2001; Schooler \& Schreiber, 2004). 


\section{Stereotyping}

The distinction between conscious and meta-conscious states also provides a way of potentially reconceptualising existing findings in the domain of stereotyping. For example, several researchers work with the notion of "aversive racists", defined as individuals who reveal evidence of implicit racism but are not conscious of their racist tendencies (e.g., Gaertner \& Dovidio, 1986; Son Hing, Chung-Yan, Grunfeld, Robichaud, \& Zanna, 2005). This idea speaks directly to the disparities that can emerge when discrepant motivations exist at different levels of consciousness. Aversive racists are identified empirically as being those individuals who score high on racism when gauged with implicit measures (i.e., the IAT) but low when gauged with explicit measures. Evidence for the importance of this distinction comes from the examination of aversive racists' evaluations of stories depicting other-race target individuals who vary with respect in the degree to which low liking ratings can be attributed to something else besides race. When aversive racists have no excuse for holding negative attitudes towards other-race individuals (e.g., when the target person is characterised as acting politely) then they behave very much like individuals with no racist tendencies. However, when there is an opportunity to justify their discriminatory behaviour in a manner that does not necessarily invoke the label racist (e.g., when the target individual behaves in slightly unfriendly manner), these individuals do act like racists. Son Hing et al. suggest that aversive racists behave in this fashion because they hold non-conscious racist views that are inconsistent with their conscious views, and can only rely on their racist tendencies when they can avoid construing them as such. However, with the distinction between consciousness and meta-consciousness there is another possibility, namely that when individuals experience racist tendencies they simply do not recognise this experience due to motivation not to take stock of racist reactions. Accordingly, when confronted with the behaviours of an individual towards whom they have racist attitudes, aversive racists experience negative affect. If a justification for this affect exists that is consistent with their views of themselves (i.e., that the individual behaved somewhat rudely), then they embrace this affect. However, when no such outlet is available they ignore it. However, critical to this account is the notion that they are actually experiencing the affect; it is simply a matter of whether or not they are prepared to allow themselves to take stock of it. Thus a reasonable alternative way to characterise aversive racists is to suggest that they experience racism but lack explicit awareness of this experience - or in the terms of meta-consciousness theory, they exhibit translation dissociations due to a motivation to not acknowledge their racist tendencies. 


\section{Implicit attitudes}

Another domain of social cognition that is naturally addressed by the distinction between consciousness and meta-consciousness is implicit attitudes (Greenwald et al., 2002). According to the standard view attitudes are either consciously held (as revealed by standard attitudinal measures) or not available to consciousness (as revealed by implicit measures such as the IAT). However, the distinction between consciousness and meta-consciousness raises the possibility that some measures that have been characterised as implicit might instead be conscious but lacking in meta-consciousness. According to this view there may be some situations in which individuals experience negative attitudes but do not acknowledge them as such, as was suggested as an interpretation of the earlier-described findings by Song Hing and colleagues. Some implicit measures may in fact tap such experienced but non-reported attitudes. In contrast, other implicit measures may tap attitudes that are truly unconscious and never experienced. This account may explain why various tests of implicit attitudes such as the IAT versus implicit priming can often be uncorrelated (Gawronski \& Payne, 2010). Some tests may be measuring truly unconscious attitudes, whereas others may be measuring attitudes that are experienced but occur without metaawareness.

\section{Faulty theories}

Finally, translation dissociations can occur if individuals have a faulty theory about what they should be feeling in a particular situation, which then colours their appraisal of their actual experience. Individuals' theories of how they think they should feel may also colour their retrospective appraisal of prior experiences.

One set of studies in which we explored this possibility dealt with the fascinating, yet controversial, domain of childhood memory and childhood happiness. The idea here is that at least some aspects of the answer to the question "How happy was your childhood?" are constructed using one's naïve theories of how one "must have felt". One cue to this assessment comes from cognitive outcomes, such as one's memory for the period, with the bridge linking memory and happiness provided by naïve theories. To investigate this process Winkielman and Schwarz (2001) first asked participants to recall few (easy task) or many (difficult task) examples from their childhood. Then participants were asked to evaluate the quality of their childhood. After completion of the recall task, but prior to rating their childhood happiness, participants were provided with two different theories. Some participants were told that psychologists have found that poor childhood memory indicates an unhappy childhood, because many 
unpleasant experiences are purged from memory. Others were told that psychologists have found that poor childhood memory indicates a happy childhood, because many unpleasant experiences are ruminated upon. For both groups it was emphasised that these are poorly supported hypotheses, and that the relevant evidence is limited to small and unusual clinical samples, making it worthwhile to test these hypotheses with a general college population. As predicted, participants' ratings of their childhood depended on the subjective theory offered to them. Finding it difficult to retrieve many childhood events, participants who were told that happy events fade from memory evaluated their childhood as happier than did participants who were told that bad events fade from memory.

Distortions in retrospective meta-awareness may also be one reason why individuals come to characterise childhood abuse experiences as having been previously forgotten (Schooler, 2001). Recent evidence suggests that characterisations of abuse experiences as having been long forgotten and suddenly remembered may at least sometimes be the result of meta-cognitive failures in which individuals overestimate the degree to which the memory was previously forgotten (Geraerts et al., 2008; Schooler et al., 2001). One factor that may contribute to such distortions is faulty theorising in which individuals assume that they must have been traumatised at the time, and therefore the only way they could fail to recall having thought about the trauma subsequently is because it was repressed. Evidence in partial support of this view comes from a survey study (Joslyn \& Schooler, 2006) in which participants' recollections of prior inappropriate sexual experiences were influenced by the manner in which questions about the experience were asked. Participants were asked to define what experiences constitute sexual abuse either before or after they were asked if those experiences had ever happened to them. Individuals who defined sexual abuse before considering whether they had been abused themselves were more likely to define themselves as having been abused, and reported being more upset at the time that the event occurred. Apparently, thinking about the experience in the context of sexual abuse invoked theories about how upsetting the experience must have been, which in turn coloured the way they recalled feeling at the time. If, as adults, individuals believe they were more traumatised by abuse then they actually were as children, then the experience may not have been as significant at the time, and thus no special forgetting mechanisms may have been required for the experience to have been forgotten.

\section{Unconscious or not meta-conscious?}

So, how can we empirically distinguish between processes that are genuinely unconscious or conscious but not meta-aware? This is tricky, as a failure of 
verbal report could result from either an absence of an experience or an absence of meta-awareness. Distinguishing between these alternatives is not easy, as the very same findings can often be reasonably construed from either perspective. For example, Winkielman and Berridge (2004) interpret findings of indirect measures revealing unreported affective states as evidence for unconscious emotion, whereas Schooler and Schreiber (2004) interpret the same types of data as suggesting affective experience without meta-awareness. At present it is very difficult to distinguish between these two accounts, however future studies may help to adjudicate between them. Here we suggest several ideas about how this could be done.

Targeting consciousness. If unreported states are indeed represented in consciousness, then in principle they should be influenced by manipulations targeting consciousness. For example, cognitive load should interfere with the operation of a conscious processes but not an unconscious process. In another example, requests for explicit monitoring should distort or simply change (diminish, amplify) conscious but not unconscious processes.

Retrospective reports. Experiences in the absence of meta-awareness can also be revealed retrospectively. For example, it is possible to catch conscious, but not meta-aware states with the external probe procedure, which, as described earlier, was successfully used in research on zoning out and unnoticed unwanted thoughts. In principle, similar strategies could be used in other paradigms. For example, perhaps individuals who fail to spontaneously report a goal (e.g., competition) could be caught consciously experiencing such goal states if probed at the right time (Bargh, 1997). It may also be possible to refine individuals' ability to carefully scrutinise their prior state. For example, if individuals are experiencing something without meta-awareness at the time, then in principle it may be possible to have people later recall their old state when given some additional source of selfinsight (e.g., mindfulness training) or by removing biases due to motivation. For example, individuals going through the break-up of a romantic relationship may retrospectively recognise past experiences of jealously or anger that had previously escaped meta-awareness. Of course retrospective analyses have their own pitfalls, as it is possible to infer states that may not have actually been experienced at the time (Joslyn \& Schooler, 2006). However, if individuals are capable of retrospectively reporting states for which they lack a basis for inference (e.g., determining whether they were subject to subliminally presented mood manipulations) then the conclusion that the state was experienced seems reasonable.

Neuroscience measures. Recent years brought some very exciting neuroscientific discoveries on the mechanisms of conscious access. Evidence 
suggests that consciousness represents a form of multi-regional activation, which is perhaps integrated by oscillatory activity and recurrent feedback (Lamme, 2004; Singer, 2000; Tononi, 2004). For example, conscious perception of a stimulus is associated with a synchronous activation of higher associative cortices, particularly parietal, prefrontal, and anterior cingulate areas, whereas unconscious perception is associated only with a local activation (Dehaene et al., 2006).

Consistent with these ideas, clinical work has shown that patients in a pervasive vegetative state (awake but unconscious) show only localised, modality-specific responses to stimuli, whereas patients in a minimally conscious state show coherent responses across multiple sensory and associative systems (Laureys et al., 2002). This is very important work as, in those cases, the difference between being unconscious and conscious can sometimes mean the difference between life and death (Caplan, McCartney, $\&$ Sisti, 2006). Of course, one should keep in mind that these investigations concern severe neurological cases where an entire person is unconscious, and may not be directly relevant to our understanding of mechanisms governing consciousness of individual mental states. Still, these discoveries open the door to bringing similar evidence into the debates between conscious and unconscious states. Thus if neuroscience measures suggest that an affective state is only locally represented, it would reduce the probability that the absence of verbal report is due to the failure of meta-consciousness. Alternatively, if affective states are associated with neurocognitive or physiological measures that suggest more global representation this would suggest translation dissociations (Schooler \& Mauss, 2010) Ultimately determination of whether or not unreported states are genuinely unconscious, or experienced but not meta-aware will come down to an assessment of the preponderance of evidence in each case.

\section{SUMMARY AND CONCLUSIONS}

Our goal in this paper was to offer a fresh perspective on consciousness in social cognition. We distinguished between unconscious, conscious, and meta-aware events and discussed dissociations between different levels of representations. This perspective can incorporate much of the existing evidence for the role of unconscious processes (Bargh, 1997) as well as evidence highlighting the critical role of conscious experience (Kihlstrom, 2008). In addition, our perspective draws attention to several interesting new issues, such as that seemingly unconscious events may simply be lacking in meta-awareness, and that mismatches between conscious and metaconscious events can reflect failures of concurrent and temporal translation. Further, our perspective specifies several ways in which researchers can empirically address the debates about whether information is unconscious, 
conscious, and metaconscious. Throughout this discussion we hoped to show that our perspective offers interesting insights on classic issues of social psychology, including the role of affect and motivation, self-awareness, autobiographical memory, well-being appraisal, thought suppression, reasoning, attitudes, and stereotyping

In conclusion, clearly there is much (if not most) that social psychology (and science in general) still does not understand about consciousness. On the other hand, recently there has also been a remarkable progress in attempts to put this inherently fuzzy topic on firm empirical ground. Unlike some other researchers we do not see the field as converging on the conclusion that consciousness is unimportant. Instead we see the field as being better and better able to provide a more comprehensive understanding of the role of unconscious, conscious, and meta-conscious states in how people think, feel, and act.

\section{REFERENCES}

Adams, H. E., Wright, L. W., \& Lohr, B. A. (1996). Is homophobia associated with homosexual arousal? Journal of Abnormal Psychology, 105, 440-445.

Baars, B. J. (1988). A cognitive theory of consciousness. Cambridge, UK: Cambridge University Press.

Bargh, J. A. (1989). Conditional automaticity: Varieties of automatic influence in social perception and cognition. In J. S. Uleman \& J. A. Bargh (Eds.), Unintended thought (pp. 3-51). New York: Guilford Press.

Bargh, J. A. (1997). Advances in social cognition. In R. S. Wyer Jr. (Ed.), The automaticity of everyday life (pp. 1-61). Mahwah, NJ: Lawrence Erlbaum Associates Inc.

Barner, D., Li, P., \& Snedeker, J. (2010). Words as windows to thought: The case of object representation. Current Directions in Psychological Science, 19, 195-200.

Baumeister, R. F., \& Masicampo, E. J. (2010). Conscious thought is for facilitating social and cultural interactions: How simulations serve the animal-culture interface. Psychological Review, 117, 945-971.

Berridge, K. C. (2003). Comparing the emotional brain of humans and other animals. In R. J. Davidson, H. H. Goldsmith, \& K. Scherer (Eds.), Handbook of affective sciences (pp. 25-51). Oxford, UK: Oxford University Press.

Block, N. (1995). On a confusion about a function of consciousness. Behavioural and Brain Sciences, 18, 27-287.

Bornemann, B., Winkielman, P., \& Van der Meer (in press). Can you feel what you don't see? Using internal feedback to detect briefly presented emotional stimuli. International Journal of Psychophysiology.

Brandimonte, M. A., Schooler, J. W., \& Gabbino, P. (1997). Attenuating verbal overshadowing through visual retrieval cues. Journal of Experimental Psychology: Learning, Memory, and Cognition, 23, 915-931.

Caplan, A., McCartney, J. J., \& Sisti, D., (2006). The case of Terri Schiavo: Ethics at the end of life. London: Prometheus Books.

Cheyene J. A., Carriere J. S. A., \& Smilek D. (2006). Absent-mindedness: Lapses of conscious awareness and everyday cognitive failures. Consciousness \& Cognition, 3, 578-592.

Chin, J. \& Schooler, J. W. (2009). Meta-awareness. In W. P. Banks (Ed.), Encyclopedia of consciousness (Vol. 2). Oxford, UK: Elsevier. 
Christoff, K., Gordon, A. M., Smallwood, J., Smith, R., \& Schooler, J. W. (2009). Experience sampling during fMRI reveals default network and executive system contributions to mind wandering. Proceedings of the National Academy of Sciences, 106, 8719-8724.

Cleeremans, A. (2005). Computational correlates of consciousness. Progress in Brain Research, $150,81-98$.

Clore, G. L. (1994). Why emotions are never unconscious. In P. Ekman \& R. J. Davidson (Eds.), The nature of emotion: fundamental questions (pp. 285-290). New York: Oxford University Press.

Custers, R., \& Aarts, H. (2010). The unconscious will: How the pursuit of goals operates outside of conscious awareness. Science, 329, 47-50.

Dehaene, S., Changeux, J. P., Naccache, L., Sackur, J., \& Sergent, C. (2006). Conscious, preconscious, and subliminal processing: A testable taxonomy. Trends in Cognitive Sciences, $10,204-211$.

Ferguson, M. J. (2007). On the automatic evaluation of end-states. Journal of Personality and Social Psychology, 92, 596-611.

Fishman, D., Smallwood, J., \& Schooler, J. W. (2006). Unwanted and meta-unknown. Unpublished manuscript.

Gaertner, S. L., \& J. F. Dovidio. (1986). The aversive form of racism. In J. F. Dovidio \& S. L. Gaertner (Eds.), Prejudice, discrimination and racism: Theory and research (pp. 61-89). Orlando, FL: Academic Press.

Gawronski, B., \& Payne, B. K. (Eds.). (2010). Handbook of implicit social cognition: Measurement, theory, and applications. New York: Guilford Press.

Geraerts, E., Lindsay, D. S., Merckelbach, H., Jelicic, M., Raymaekers, L., Arnold, M. M., et al. (2008). Cognitive mechanisms underlying recovered memory experiences of childhood sexual abuse. Psychological Science, 20, 1.

Gibbons, F. X. (1990). Self-attention and behaviour: A review and theoretical update. M. P. Zanna (Ed.), Advances in experimental social psychology (pp. 249-303). New York: Academic Press.

Greenwald, A. G. (1992). New Look 3: Reclaiming unconscious cognition. American Psychologist, 47, 766-779.

Greenwald, A. G., Banaji, M. R., Rudman, L. A., Farnham, S. D., Nosek, B. A., \& Mellott, D. S. (2002). A unified theory of implicit attitudes, stereotypes, self-esteem, and self-concept. Psychological Review, 109, 3-25.

Hazy, T. E., Frank, M. J. \& O'Reilly, R. C. (2007). Towards an executive without a homunculus: Computational models of the prefrontal cortex/basal ganglia system. Philosophical Transactions of the Royal Society B, 362, 1601-1613.

Hull, J. G. (1981). A self-awareness model of the causes and effects of alcohol consumption. Journal of Abnormal Psychology, 90, 586-600.

Joslyn, S., \& Schooler, J. W. (2006). Influences of the present on the past: The impact of interpretation on memory for abuse. In L. G. Nilsson \& N. Ohta (Eds.), Memory and society: Psychological perspectives. Hove, UK: Psychology Press.

Kahneman, D., Krueger, A. B., Schkade, D., Schwarz, N., \& Stone, A. A. (2004). A survey method for characterising daily life experience: The Day Reconstruction Method (DRM). Science, 306, 1776-1780.

Kihlstrom, J. F. (2007). The psychological unconscious. In O. John, R. Robins, \& L. Pervin (Eds.), Handbook of personality: Theory and research (3rd ed.). New York: Guilford Press.

Kihlstrom, J. F. (2008). The automaticity juggernaut. In J. Baer, J. C. Kaufman, \& R. F. Baumeister (Eds.), Are we free? Psychology and free will (pp. 155-180). New York: Oxford University Press.

Koriat, A. (2006) Metacognition and consciousness. In Cambridge handbook of consciousness. New York: Cambridge University Press. 
Lambie, J. A., \& Marcel, A. J. (2002). Consciousness and the varieties of emotion experience: A theoretical framework. Psychological Review, 109, 219-259.

Lamme, V. A. F. (2004). Separate neural definitions of visual consciousness and visual attention: A case for phenomenal awareness. Neural Networks, 17, 861-872.

Laureys, S., Antoine, S., Boly, M., Elincx, S., Faymonville, M. E., Berre J., et al. (2002). Brain function in the vegetative state. Acta Neurologica Belgica, 102, 177-185.

LeDoux, J. (1996). The emotional brain: The mysterious underpinnings of emotional life. New York: Simon \& Schuster.

Mangan, B. (2001). Sensation's ghost: The non-sensory 'fringe' of consciousness. Psyche, 7, 18.

Mead, G. H. (1934). Mind, self, \& society. Chicago, IL: University of Chicago Press.

Melcher, J., \& Schooler, J. W. (1996). The misremembrance of wines past: Verbal and perceptual expertise differentially mediate verbal overshadowing of taste. The Journal of Memory and Language, 35, 231-245.

Milner, D., \& Goodale, M., (1995). The visual brain in action. Oxford, UK: Oxford University Press.

Mitchell, J. M., Mason, M. F., Macrae, C. N., \& Banaji, M. R. (2006). Thinking about others: The neural substrates of social cognition. In J. Cacioppo (Ed.), Social neuroscience: People thinking about people. Cambridge, MA: MIT Press.

Murphy, S. T., \& Zajonc, R. B. (1993). Affect, cognition, and awareness: Affective priming with optimal and suboptimal stimulus exposures. Journal of Personality and Social Psychology, 64, 723-739.

Öhman, A., Flykt, A., \& Lundqvist, D. (2000). Unconscious emotion: Evolutionary perspectives, psychophysiological data and neuropsychological mechanisms. In R. D. Lane, L. Nadel, \& G. Ahern (Eds.), Cognitive neuroscience of emotion (pp. 296-327). New York: Oxford University Press.

Robinson, T. E., \& Berridge, K. C. (1993). The neural basis of drug craving: an incentivesensitization theory of addiction. Brain Research Reviews, 18, 247-291.

Rosenthal, D. (1986). Two concepts of consciousness. Philosophical Studies, 49, 329-359.

Sayette, M. A., Reichle, E. D., \& Schooler, J. W., (2009) Lost in the sauce: The effects of alcohol on mind-wandering. Psychological Science, 20, 747-752.

Sayette, M. A., Schooler, J. W., \& Reichle, E. D. (2010). Out for a smoke: The impact of cigarette craving on zoning-out during reading. Psychological Science, 21, $26-30$.

Schooler, J., \& Schreiber, C. A. (2004), Experience, meta-consciousness, and the paradox of introspection. Journal of Consciousness Studies, 11(7-8), 17-39.

Schooler, J. W. (2001). Discovering memories in the light of meta-awareness. The Journal of Aggression, Maltreatment and Trauma, 4, 105-136.

Schooler, J. W. (2002). Re-representing consciousness: Dissociations between consciousness and meta-consciousness. Trends in Cognitive Science, 6, 339-344.

Schooler, J. W., Ariely D., \& Loewenstein, G. (2003). The pursuit and assessment of happiness can be self-defeating. In I. Brocas \& J. Carrillo (Eds.), The psychology of economic decisions. Oxford, UK: Oxford University Press.

Schooler, J. W., \& Engstler-Schooler, T. Y. (1990). Verbal overshadowing of visual memories: Some things are better left unsaid. Cognitive Psychology, 17, 36-71.

Schooler, J. W., Fiore, S. M., \& Brandimonte, M. A. (1997). At a loss from words: Verbal overshadowing of perceptual memories. In D. L. Medin (Ed.), The psychology of learning and motivation (pp. 293-334). San Diego, CA: Academic Press.

Schooler, J. W., \& Mauss, I. B. (2010). To be happy and to know it: The experience and metaawareness of pleasure. In K. Berridge \& M. Kringlebach (Eds.), Pleasures of the brain Oxford, UK: Oxford University Press. 
Schooler, J. W., McSpadden, M., Reichle, E. D., \& Smallwood, J. (2010). Unnoticed nonsense: Mind-wandering can prevent people from realizing that they are reading gibberish. Manuscript submitted for publication.

Schooler, J. W., Ohlsson, S., \& Brooks, K. (1993). Thoughts beyond words: When language overshadows insight. Journal of Experimental Psychology: General, 122, 166183.

Schooler, J. W., Reichle, E. D., \& Halpern, D. V. (2005). Zoning-out during reading: Evidence for dissociations between experience and meta-consciousness. In D. T. Levin (Ed.), Thinking and seeing: Visual metacognition in adults and children (pp. 204-226). Cambridge, MA: MIT Press.

Schooler, J. W., \& Schreiber, C. (2005). To know or not to know: Consciousness, metaconsciousness, and motivation. In J. P. Forgas, K. R. Williams, \& W. von Hippel (Eds.), Social motivation: Conscious and non-conscious processes (pp. 351-372) New York: Cambridge University Press.

Schwarz, N. (1990). Feelings as information: Informational and motivational functions of affective states. In Handbook of motivation and cognition: Foundations of social behaviour (Vol. 2, pp. 527-561). New York: Guilford Press.

Schwarz, N., \& Clore, G. L. (1983). Mood, misattribution, and judgements of well being: Informative and directive functions of affective states. Journal of Personality and Social Psychology, 45, 513-523.

Shiffrin, R. M., \& Schneider, W. (1977). Controlled and automatic human information processing: II. Perceptual learning, automatic attending and a general theory. Psychological Review, 84, 127-190.

Sieck, W. R., Quinn, C. N., \& Schooler, J. W. (1999). Justification effects on the judgement of analogy. Memory and Cognition, 27, 844-855.

Singer, W. (2000). Phenomenal awareness and consciousness from a neurobiological perspective. In T. Metzinger (Ed.), Neural correlates of consciousness: Empirical and conceptual questions (pp. 121-138). Cambridge, MA: MIT Press.

Smallwood, J., McSpadden, M., \& Schooler, J. (2008) When attention matters: The curious incident of the wandering mind. Memory and Cognition, 36, 1144-1150.

Smallwood, J., \& Schooler, J. W. (2006). The restless mind. Psychological Bulletin, 132, $946-$ 958.

Son Hing, L. S., Chung-Yan, G., Grunfeld, R., Robichaud, L., \& Zanna, M. P. (2005). Exploring the discrepancy between implicit and explicit prejudice: A test of aversive racism theory. In J. P. Forgas, K. Williams, \& S. Latham (Eds.), Social motivation: Conscious and unconscious processes (Vol. 5. The Sydney Symposium of Social Psychology, pp. 274-293). New York: Psychology Press.

Sperling, G. (1960). The information available in brief visual presentation, Psychological Monographs, 74, 11.

Starr, M. J., Lin, J., \& Winkielman, P. (2007). The impact of unconscious facial expressions on consumption behaviour involves changes in positive affect: Evidence from EMG and appetitive reflex-modulation. Poster presented at 47th Annual Meeting of Society for Psychophysiological Research, Savannah, GA.

Starr, M. J., Winkielman, P., \& Gogolushko, K. (2008). Influence of affective pictures and words on consumption behaviour and facial expressions. Poster presented at The Society for Psychophysiological Research, Austin, TX.

Tiffany S. T. (1990). A cognitive model of drug urges and drug-use behaviour: Role of automatic and nonautomatic processes. Psychological Review, 97, 147-168.

Tononi, G. (2004). An information integration theory of consciousness. BMC Neuroscience, 5, 42.

Vygotsky, L. S. (1962). Thought and language. Cambridge, MA: MIT Press. 
Watson, D., Clark, L. A., \& Tellegen, A. (1988). Development and validation of brief measures of positive and negative affect: The PANAS scales. Journal of Personality \& Social Psychology, 54, 1063-1070.

Wegner, D. M. (1994). Ironic processes of mental control. Psychological Review, 101, 34-52.

Wegner, D. M., \& Smart, L. (1997). Deep cognitive activation: A new approach to the unconscious. Journal of Consulting and Clinical Psychology, 65, 984-995.

Weiskrantz, L. (1986). Blindsight: A case study and its implications. Oxford, UK: Oxford University Press.

Wicklund, R. A. (1975). Objective self awareness. In L. Berkowitz (Ed.), Advances in experimental social psychology (Vol. 8). New York: Academic Press.

Wilson, S. J., Sayette, M. A., \& Fiez, J. A. (2004). Pre-frontal responses to drug cues: A neurocognitive analysis. Nature Neuroscience, 7, 211-214.

Wilson, T. D., Lisle, D. J., Schooler, J. W., Hodges, S. D., Klaaren, K. J., \& LaFleur, S. J. (1993). Introspecting about reasons can reduce post-choice satisfaction. Personality and Social Psychology Bulletin, 19, 331-339.

Wilson, T. D., \& Schooler, J. W. (1991). Thinking too much: Introspection can reduce the quality of preferences and decisions. Journal of Personality and Social Psychology, 60, 181-192.

Winkielman, P. (2002). When knowing more leads you astray: The effects of self-focus on accuracy of causal reports. Polish Psychological Bulletin, 33, 5-12.

Winkielman, P., \& Berridge, K. C. (2004). Unconscious emotion. Current Directions in Psychological Science, 13, 120-123.

Winkielman, P., Berridge, K., \& Sher, S. (2011). Emotion, consciousness, and social behaviour. In J. Decety \& J. T. Cacioppo (Eds.), Handbook of social neuroscience (pp. 195-211). Oxford, UK: Oxford University Press.

Winkielman, P., Berridge, K. C., \& Wilbarger, J. L. (2005a). Emotion, behaviour, and conscious experience: Once more without feeling. In L. Feldman-Barrett, P. Niedenthal, \& P. Winkielman (Eds.), Emotion and consciousness. New York: Guilford Press.

Winkielman, P., Berridge, K. C., \& Wilbarger, J. L. (2005b). Unconscious affective reactions to masked happy versus angry faces influence consumption behaviour and judgements of value. Personality and Social Psychology Bulletin, 1, 121-135.

Winkielman, P., Knutson, B., Paulus, M. P., \& Trujillo, J. T. (2007). Affective influence on decisions: Moving towards the core mechanisms. Review of General Psychology, 11, 179192.

Winkielman, P., \& Schwarz, N. (2001). How pleasant was your childhood? Beliefs about memory shape inferences from experienced difficulty of recall. Psychological Science, 12, 176-179.

Winkielman, P., Zajonc, R. B., \& Schwarz, N. (1997). Subliminal affective priming resists attributional interventions. Cognition and Emotion, 11, 433-465.

Zajonc, R. B. (1994). Evidence for nonconscious emotions. In P. Ekman \& R. J. Davidson (Eds.), The nature of emotion: Fundamental questions (pp. 293-297). New York: Oxford University Press.

Zeeman, A. 2002, Consciousness: A user's guide New Haven, CT: Yale University Press. 